International Journal of Current Advanced Research

ISSN: O: 2319-6475, ISSN: P: 2319 - 6505, Impact Factor: SJIF: 5.995

Available Online at www.journalijcar.org

Volume 6; Issue 5; May 2017; Page No. 3848-3851

DOI: http://dx.doi.org/10.24327/ijcar.2017.3851.0380

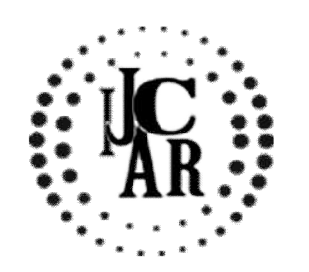

Research Article

\title{
USES OF COLD PLASMA IN CONSERVATIVE DENTISTRY AND ENDODONTICS
}

\author{
Hema.V and Subash Sharma
}

Saveetha Dental College. 162, P.H.Road, Saveetha Dental College, Vellapanchavadi, Chennai-77

\begin{tabular}{|c|c|}
\hline A R T I C L E & A B S T R A C T \\
\hline Article History: & $\begin{array}{l}\text { Aim: To recapitulate the possible applications of non- thermal plasma in conservative } \\
\text { dentistry and endodontics. }\end{array}$ \\
\hline $\begin{array}{l}\text { Received } 25^{\text {th }} \text { February, } 2017 \\
\text { Received in revised form } 2^{\text {nd }} \text { March, } 2017 \\
\text { Accepted } 15^{\text {th }} \text { April, } 2017\end{array}$ & $\begin{array}{l}\text { Objective: Non- thermal plasma is lately being researched for its applications in dentistry } \\
\text { and cancer therapy. The objective of this review is to summarize the possible role of Non- } \\
\text { thermal plasma in conservative dentistry and endodontics. }\end{array}$ \\
\hline Published online $28^{\mathrm{um}}$ May, 2017 & $\begin{array}{l}\text { Background: Plasma is the fourth state of matter and also the most form, the other three } \\
\text { being air, water and solid. Plasma is ionised form of gas and is of two types: thermal and }\end{array}$ \\
\hline Key words: & non- thermal or cold atmospheric plasma. The cold atmospheric plasma based dental \\
\hline $\begin{array}{l}\text { Cold plasma, non-thermal plasma, biofilms, } \\
\text { bond strength, adhesive, tooth whitening, } \\
\text { hydrogen peroxide. }\end{array}$ & $\begin{array}{l}\text { applications is being investigated recently in fields such as root canal disinfection, tooth } \\
\text { whitening, sterilization, deactivation of oral biofilms, enhancement of strength of light cure } \\
\text { restorations and cancer therapy. } \\
\text { Reason: Cold atmospheric plasma may be of a great use in dentistry due to its properties. } \\
\text { This review is to recapitulate and bring to light the possible uses of cold atmospheric } \\
\text { plasma in conservative dentistry and endodontics. }\end{array}$ \\
\hline
\end{tabular}

Copyright $₫ 2017$ Hema.V and Subash Sharma. This is an open access article distributed under the Creative Commons Attribution License, which permits unrestricted use, distribution, and reproduction in any medium, provided the original work is properly cited.

\section{INTRODUCTION}

The three states of matter, solid, liquid and gas are relatively well known. Plasma which is an ionised gas is considered as the fourth state of matter. It is found naturally (upper part of earth's atmosphere) and can also be produced artificially. It is a mixture of ions, electrons, neutral atoms and molecules ${ }^{1}$. Based on their temperature plasmas can be categorized into thermal (high temperature) and non-thermal plasmas (cold or low temperature). In thermal plasma, the component particles are in thermal equilibrium with each other. In non-thermal or cold plasmas the larger molecules comprising the gas, ions and atoms remain at low temperatures while the electrons are accelerated. Thermal plasmas are associated with electric sparks, flames, lightening, the sun and the stars. Cold plasmas are seen in fluorescent lighting tubes, neon tubes and plasma $\mathrm{TVs}^{2}$.

Plasmas operated at lower temperatures have attracted a lot of interest due to its use in applications such as surface treatment, food processing, thin-film deposition and biomedicine. In the medical field, the use of non-thermal plasma in applications such as sterilization of living tissues, sterilization of non-living objects for medical applications, blood coagulation, wound healing and tissue regeneration and cancer therapy have been studied ${ }^{3}$. Apart from these applications, studies have been carried out to find out the

*Corresponding author: Hema.V

Saveetha Dental College. 162, P.H.Road, Saveetha Dental

College, Vellapanchavadi, Chennai-77 possible uses of cold plasma in dentistry. The dental applications that have been experimented are inactivation of oral microorganisms associated with periodontal diseases, dental caries, root canal disinfection, surface modifications of dentine and implants, polymerization and tooth bleaching ${ }^{4-10}$.

\section{Cold plasma/ Non-thermal atmospheric pressure plasma}

The temperature of non-thermal plasma is $104^{\circ} \mathrm{F}$ at the point of application. Energy is required to produce plasma. Electric, light or thermal energy can be used. Cold plasma can be produced using different gases such as Helium, Argon, Nitrogen, Heliox (a mix of helium and oxygen), and air. Some methods used to produce cold atmospheric plasma are Dielectric Barrier Discharge (DBD), Atmospheric Pressure Plasma Jet (APPJ), plasma needle, and plasma pencil ${ }^{11}$.

The non-equilibrium nature of atmospheric plasma with gas phase at low temperatures and highly reactive particles, allows it to be directly applied to living tissues at safe temperatures. The highly reactive plasma species clean, etch, modify, form a thin layer of plasma coating or react with the surface they come into contact with, depending on the gas composition. This characteristic feature of plasma has been used in various fields ${ }^{12,13}$.

The surface interaction is based on the excited particles produced by the ionised gas with an essential equal density of positive and negative charges. These excited particles will decay and excite other particles, thus reacting with the surface in a dry chemical way ${ }^{14}$. The reactive species created in 
plasma are short lived ${ }^{15}$. Thus, surface treatment by plasmas can clean and improve the bonding characteristics of polymers by changing the surface energy of materials ${ }^{16}$.

\section{Applications of cold plasma in endodontics}

The non-thermal atmospheric plasma was effective in disinfection of root canals. The conventional methods of disinfecting the root canals include mechanical debridement, chemical irrigation, laser irradiation, and ultrasound. These methods cannot achieve complete disinfection of endodontic sites $^{17}$. The failure of endodontic treatment is frequently caused by Enterococcus faecalis ${ }^{18}$. Many studies have been done to investigate the disinfection of root canals using plasma-based approaches.

The study by Jiang $\mathrm{C}$ et al was the first to demonstrate the effectiveness of plasma mediated removal of bacterial biofilms from root canal surfaces and dentinal tubules. He and $\mathrm{He} /(1 \%) \mathrm{O} 2$ plasmas were used. Complete inhibition of Bacillus atrophaeus on nutrient agar plates on exposure to $\mathrm{He}$ and $\mathrm{He} /(1 \%) \mathrm{O} 2$ plasmas for 60 seconds was observed. He/ (1\%) $\mathrm{O} 2$ plasma was shown to be more effective than $\mathrm{He}$ alone for eradication of Bacillus atrophaeus. A 180 seconds treatment with $\mathrm{He} /(1 \%) \mathrm{O} 2$ plasma disinfected human tooth root canal with saliva-derived biofilms ${ }^{6}$.

The antibacterial effects of cold plasma against Enterococcus faecalis in vitro was evaluated by $\mathrm{Du} \mathrm{T}$ et al. The study showed that treatment of E.faecalis biofilms on tissue culture plates for 5 minutes with atmospheric pressure nonequilibrium plasma or $2 \%$ chlorhexidine killed majority of the bacteria in biofilms. Infected single rooted teeth were also exposed to atmospheric pressure non- equilibrium plasma or 2\% CHX for 5, 10 and 15 minutes. Bacterial survival remarkably reduced with increased exposure times with atmospheric pressure non- equilibrium plasma and $2 \% \mathrm{CHX}$. ANAP was found to be as effective as $2 \%$ chlorhexidine for inactivating bacteria in infected root canals ${ }^{19}$.

Jie Pan et al also studied the disinfection of tooth root canal with E. faecalis biofilms in vitro using cold plasma. Seventy single rooted teeth infected with E.faecalis biofilms were divided into 7 groups. The group 1 was the negative control group which received no treatment. Group 7 was treated with calcium hydroxide intracanal medication for 7 days. Groups 2 to 6 were treated with cold plasma for 2,4,6,8 and 10 minutes respectively. A single electrode nonthermal atmospheric pressure plasma jet was used to treat the E. faecalis biofilms. The results of the study showed that, compared with the positive control group, cold plasma treatment of 8 or 10 minutes (groups 5 and 6) had a significantly higher anti microbial efficacy ${ }^{20}$.

\section{Applications of cold plasma in conservative dentistry:}

\section{Influence of cold plasma in bond strength of composite resin restoration}

In conventional composite resin restorations, the connection between resin and intact dentin is brought about by the adhesive or bonding agent. The penetration and subsequent polymerization of the adhesive monomers increases the bond strength. Incomplete penetration will lead to leakage and disruption of the hybrid layer ${ }^{21}$. Resin adhesive penetration into the demineralised dentin under the influence of plasma treatment was studied by $\mathrm{Y}$ Zhang et al. Extracted, non- carious, unerupted human third molars were used. The prepared dentin surfaces were etched and sectioned perpendicularly. The separated halves were randomly treated with argon plasma brush or gentle argon air blowing for 30 seconds. The specimens were then applied with a model adhesive containing BisGMA and HEMA, gently air dried for 5 seconds and light cured for 20 seconds. The results revealed higher content of adhesive at the adhesive/dentin interface in plasma treated specimens as compared to controls. The penetration of HEMA was especially enhanced. Plasma treatment could also improve the polymerization at the interface ${ }^{7}$.

Other similar studies by Dong X et al and Ritts AC et al also revealed that plasma treatment improved the interfacial bonding strength ${ }^{22,23}$.

The effectiveness of cold plasma for inducing polymerization of model self -etch adhesives was studied by Chen $\mathrm{M}$ et al. Monomer/water mixtures with varying mass ratios of monomers were treated with non-thermal atmospheric plasma brush for 40 seconds at $32^{\circ}$ to $35^{\circ} \mathrm{C}$. For comparison, photoinitiators were added to the mixtures, which were light- cured for 40 seconds. The results of the research indicated that nonthermal atmospheric plasma exposure induced polymerization of the photo initiator-free self-etch adhesives. The presence of water did not negatively affect the degree of conversion (DC) of plasma cured samples but caused decline in the DC of the light-cured samples. The study showed that the possibility of having dental composite restorations with enhanced properties and performance by polymerization with non-thermal atmospheric plasma brush ${ }^{9}$.

Composite resins are relatively hydrophobic when compared to enamel and wet dentin which are hydrophilic. This makes adhesion between the resin and the tooth substrate difficult. Good wettability is needed to enhance adhesion between these two substrates. Chen $\mathrm{M}$ et al studied the surface modification of dental substrates including dentin, enamel and two composites using non-thermal, atmospheric plasma brush. The study demonstrated that this device could be used effectively to improve the surface wettability of these substrates clinical setting. SEM images also indicated no significant changes in the morphology of these dental substrates ${ }^{24}$.

Cho B et al investigated the shear bond strength of composite resin to ceramic with plasma polymer coating using nonthermal atmospheric -pressure (NAP) glow discharge. A small pencil-type NAP glow discharge plasma torch was used. The study revealed that the shear bond strength (SBS) of the adhesive to ceramic surface pre-treated sequentially with water plasma and TEGDMA plasma in helium gas was significantly higher than that of the adhesive to the untreated surface $^{25}$.

\section{Tooth bleaching}

Lee et al demonstrated tooth bleaching with nonthermal atmospheric pressure plasma. A helium plasma jet device was used. Teeth were sectioned sagitally into halves and assigned to experimental and control groups randomly. The experimental group was treated with hydrogen peroxide plus plasma for 10 minutes while the control group was treated with hydrogen peroxide for the same duration. The results showed improved bleaching efficacy with hydrogen peroxide 
and plasma compared with using hydrogen peroxide alone. The surface temperatures of the teeth did not exceed $40^{\circ} \mathrm{C}$ during plasma treatment. Tooth surface proteins were seen to be noticeably removed with plasma treatment ${ }^{10}$. In addition, teeth stained with coffee or red wine could be effectively whitened using plasma jet in combination with hydrogen peroxide compared with using hydrogen peroxide alone ${ }^{26}$.

Tooth whitening using hydrogen peroxide with direct current cold atmospheric plasma microjet was demonstrated by Sun P et $a l^{27}$.

Intracoronal tooth bleaching using nonthermal atmospheric pressure plasma was studied by Park JK et al. Forty extracted, single rooted and blood stained human teeth were randomly divided into two groups. One group was treated with $30 \%$ hydrogen peroxide with nonthermal atmospheric plasma intra coronally for 30 minutes. Other group received hydrogen peroxide alone intracoronally for the same duration. The efficacy of bleaching with hydrogen peroxide and plasma was significantly higher compared to using hydrogen peroxide alone. The temperature was approximately $37^{\circ} \mathrm{C}$ during treatment with plasma ${ }^{28}$.

Kim MS et al used hybrid Ar gas- liquid plasma to produce tooth whitening. It was confirmed that tooth whitening in this study was primarily due to $\mathrm{OH}$ radicals ${ }^{29}$.

Nam et al investigated tooth bleaching using non thermal atmospheric pressure plasma (NAAP) with low concentration of hydrogen peroxide. Forty human teeth were randomly divided into four groups: $15 \%$ carbamide peroxide (CP) with NAAP, CP plus plasma arc lamp, CP plus diode laser, CP alone. $15 \%$ carbamide peroxide with NAAP showed highest bleaching efficacy with temperature during treatment around $37^{\circ} \mathrm{C}^{30}$.

Claiborne et al investigated the use of low temperature atmospheric pressure plasma (LTAPP) delivered using plasma pencil with hydrogen peroxide gel. Thirty extracted human teeth were randomly divided into two groups. One group received LTAPP with $36 \%$ hydrogen peroxide and the other group received $36 \%$ hydrogen peroxide gel only at 10,15 and 20 minutes duration in both groups. The effectiveness was significantly higher with LTAPP and $36 \%$ hydrogen peroxide compared to hydrogen peroxide alone in 10 and 20 minutes groups. The temperature in both the groups remained under $80^{\circ} \mathrm{F}$ with no possibility of thermal injury ${ }^{2}$.

\section{CONCLUSION}

The above evidence suggests that plasma may be used in conservative dentistry and endodontics for increased effectiveness of treatment using it. It is due to its non thermal nature, anti-microbial properties and ability to modify the surfaces that comes in contact. It can be used to disinfect the root canal, increase bond strength in composite restorations and in tooth bleaching.

\section{References}

1. Blumhagen A, Singh P, Mustapha A, Chen M, Wang Y, Yu Q. Plasma deactivation of oral bacteria seeded on hydroxyapatite disks as tooth enamel analogue. American journal of dentistry. 2014 Apr; 27(2):84.

2. Chen M, Zhang Y, Driver MS, Caruso AN, Yu Q, Wang Y. Surface modification of several dental substrates by non-thermal, atmospheric plasma brush. Dental Materials. 2013 Aug 31; 29(8):871-80.

3. Chen, M., Zhang, Y., Yao, X., Li, H., Yu, Q., \& Wang, Y. Effect of a non-thermal, atmospheric-pressure, plasma brush on conversion of model self-etch adhesive formulations compared to conventional photo-polymerization. Dental Materials: Official Publication of the Academy of Dental Materials, 28(12), 1232-1239.2011.

4. Cho, B., Han, G., Oh, K. et al. The effect of plasma polymer coating using atmospheric-pressure glow discharge on the shear bond strength of composite resin to ceramic. J Mater Sci (2011) 46: 2755.

5. Claiborne $\mathrm{D}$, et al. Low temperature atmospheric pressure plasma enhanced tooth whitening: the nextgeneration technology. Int J Dent Hygiene.2013

6. Dong X, Ritts AC, Staller C, Yu Q, Chen M, Wang Y. Evaluation of plasma treatment effects on improving adhesive-dentin bonding by using the same tooth controls and varying cross-sectional surface areas. European Journal of Oral Sciences. 2013; 121:355362. [PubMed: 23841788]

7. Du T, Ma J, Yang P, Xiong Z, et al. Evaluation of antibacterial effects by atmospheric pressure nonequilibrium plasmas against Enterococcus faecalis biofilms in vitro. J Endod 2012; 38:545-9.

8. Duske K, Koban I, Kindel E, Schröder K, Nebe B, Holtfreter B, Jablonowski L, Weltmann KD, Kocher T. Atmospheric plasma enhances wettability and cell spreading on dental implant metals. Journal of clinical periodontology. 2012 Apr 1; 39(4):400-7.

9. Fridman $\mathrm{G}$, et al. Applied plasma medicine. Plasma Processes and Polymers. 2008 Aug 15; 5(6):503-33.

10. Gurnett DA, et al. Introduction to plasma physics: with space and laboratory applications. Cambridge university press; 2005 Jan 6.

11. Hoffmann, C., Berganza, C., \& Zhang, J. Cold Atmospheric Plasma: methods of production and application in dentistry and oncology. Medical Gas Research, 3, 21.2013.

12. Jiang $\mathrm{C}$, Chen $\mathrm{M}$, Schaudinn $\mathrm{C}$, et al. Pulsed atmospheric-pressure cold plasma for endodontic disinfection. IEEE Trans Plasma Sci 2009; 7:1190-5.

13. Kim MS, Koo IG, Choi MY, Jung JC, Eldali F, Lee JK, Collins GJ (2012). Correlated Electrical and Optical Studies of Hybrid Argon Gas-Water Plasmas and their Application to Tooth Whitening. Plasma Processes and Polymers. 2012 Mar 1; 9(3):339-45.

14. Koban I, Holtfreter B, Hübner NO, Matthes R, Sietmann R, et al. Antimicrobial efficacy of nonthermal plasma in comparison to chlorhexidine against dental biofilms on titanium discs in vitro - proof of principle experiment. J Clin Periodontol 38: 956965.2011.

15. Lee HW, Kim GJ, Kim JM, Park JK, Lee JK, Kim GC. Tooth bleaching with nonthermal atmospheric pressure plasma. Journal of endodontics. 2009 Apr 30; 35(4):587-91.

16. Lee HW, Nam SH, Mohamed AAH, Kim GC, Lee JK. Atmospheric Pressure Plasma Jet Composed of Three Electrodes: Application to Tooth Bleaching. Plasma Process Polym 7: 274-280.2010. 
17. Liebermiann A, Keul C, Bähr N, Edelhoff D, Eichberger M, Roos M, Stawarczyk B. Impact of plasma treatment of PMMA-based CAD/CAM blanks on surface properties as well as on adhesion to selfadhesive resin composite cements. Dent Mater. 2013 Sep; 29(9):935-44.

18. Liston EM, Martinu L, Wertheimer MR. Plasma surface modification of polymers for improved adhesion: a critical review. J Adhesion Sci Technol 1993; 7: 1091-1127.

19. Mahasneh A, et al. In activation of Porphyromonas gingivalis by low-temperature atmospheric pressure plasma. Plasma Med 2013; 1:201-14.

20. Matsuo T, Shirakami T, Ozaki K, et al. An immunohistological study of the localization of bacteria invading root pulpal walls of teeth with periapical lesions. J Endod 2003; 29:194-200.

21. Nam SH, Lee HW, SH Cho JKLEE, Jeon YC, Kim GC (2013) High-efficiency tooth bleaching using non thermal atmospheric pressure plasma with low concentration of hydrogen peroxide. J Appl Oral Sci 21: 265-270.

22. Pan J, Sun K, Liang Y, Sun P, Yang X, Wang J, Zhang J, Zhu W, Fang J, Becker KH. Cold plasma therapy of a tooth root canal infected with Enterococcus faecalis biofilms in vitro. Journal of endodontics. 2013 Jan 31; 39(1):105-10.

23. Park JK, Nam SH, Kwon HC, Mohamed AA, Lee JK, Kim GC. Feasibility of nonthermal atmospheric pressure plasma for intracoronal bleaching. International endodontic journal. 2011 Feb 1; 44(2):170-5.
24. Ritts AC, Li H, Yu Q, Xu C, Yao X, Hong L, et al. Dentin surface treatment using a non-thermal argon plasma brush for interfacial bonding improvement in composite restoration. European Journal of Oral Sciences. 2010; 118(5):510-16. [PubMed: 20831586]

25. Shohet JL. Plasma Aided Manufacturing. IEEE T Plasma Sci. 1991; 19: 725-734.

26. Spencer P, Ye Q, Park J, Topp EM, Misra A, Marangos $\mathrm{O}$, et al. Adhesive/dentin interface: The weak link in the composite restoration. Annals of Biomedical Engineering. 2010; 38(6):1989-2003. [PubMed: 20195761]

27. Sun P, Pan J, Tian Y, Bai N, Wu H, Wang L, Yu C, Zhang J, Zhu W, Becker KH, Fang J (2010). Tooth whitening with hydrogen peroxide assisted by a directcurrent cold atmospheric-pressure air plasma microjet. IEEE Transactions on Plasma Science. 2010 Aug; 38(8):1892-6.

28. Sundqvist G, Figdor D, Persson S, et al. Microbiologic analysis of teeth with failed endodontic treatment and the outcome of conservative re-treatment. Oral Surg Oral Med Oral Pathol Oral Radiol Endod 1998; 85:8693.

29. Yasuda H. Luminous Chemical Vapour Deposition and Interface Engineering.2005

30. Zhang Y, Yu Q, Wang Y. Non-thermal atmospheric plasmas in dental restoration: Improved resin adhesive penetration. Journal of dentistry. 2014 Aug 31; 42(8):1033-42.

\section{How to cite this article:}

Hema.V and Subash Sharma (2017) ' Uses Of Cold Plasma In Conservative Dentistry And Endodontics', International Journal of Current Advanced Research, 06(05), pp. 3848-3851.

DOI: http://dx.doi.org/10.24327/ijcar.2017.3851.0380 